\title{
'Who's Afraid of High Def?' Institutional Factors Influencing HDTV Diffusion in the Netherlands
}

\author{
Eva Baaren, Lidwien van de Wijngaert and Erik Huizer \\ Department of Information and Computing Science, Utrecht University, Netherlands \\ baaren@cs.uu.nl; l.vandeWijngaert@cs.uu.nl; huizer@cs.uu.nl
}

\begin{abstract}
Since digital HDTV has made an entrance in the Netherlands, 'HD ready' TV sets are sold and HDTV cable subscription services are available. In contrast, no Dutch TV channel offers HD content and publicity is mostly negative. This paper analyses the economical, organizational, historical and cultural background of $H D$ diffusion in the Netherlands. Results show that the diffusion of HDTV is influenced by international standardization of peripheral equipment, competing TV uses and a deadlock in content broadcasting.
\end{abstract}

\section{Introduction}

Since the beginning of television, developments of new technological standards for this medium have focused on creating more 'realistic' viewing experience. After the introduction of color TV in the 1960's, a new analog image line standard was introduced in the late 80 's, called 'high definition television' or HDTV. In Europe, before it could be introduced to the public, it was abandoned by the industry that started concentrating on a digital television standard coming from the U.S. (Agterberg, 2007). Since 2004, HDTV came back to Europe in its digital form and has been introduced to the public. In the Netherlands, electronics stores nowadays sell TV sets that are HDcompatible. Also, the World Soccer Games in Portugal were broadcast in HD format in June 2006 and, as a result, cable distributors that were involved in this project started offering subscriptions with HDTV channels. However, these subscriptions still only consist of three or four foreign owned HD channels, while the major Dutch channels are still shown in standard definition (SD). Furthermore, newspapers and consumer magazines report of incompatibility of DVD standards, lack of HD productions and limited bandwidth for telecom providers (Sombroek 2006, Hijink 2006, Libbenga 2007, Boogert 2006b). Consequently, the diffusion of this new TV form seems not at all flawless, and the question can be raised what factors contribute to this situation. While the diffusion of a new medium depends on decision-making of both the television institutions and the public, in this paper, factors influencing the institutions will be explained, since they have the power and the tools to determine if and how content, subscription services and devices are offered. They also have the power to promote HDTV as a new television form, according to their own convenience and business strategies (Boddy, 2003). The question will therefore be: What factors determine the diffusion of HDTV on the supply side? Answering this question will give insights in the way HDTV is currently deployed by the Dutch supply chain and, with that, what this deployment means for its diffusion.

\section{HDTV as a technology}

Nowadays, when HDTV is spoken of by institutions, it stands for an image resolution of either 1280 vertical by 720 horizontal pixels or 1920 vertical by 1080 horizontal pixels. Furthermore, the displaying of HDTV images is done by either interlaced (i) or progressive (p) scan techniques. Interlaced scanning displays half of the total lines of a picture at once, followed by the other half. Progressive scanning displays all the available lines at once and works with 50 frames per second (Miller, 2006). Combining resolution, displaying form and frame refresh rate, the common HDTV standards are 720p50 (1280x720 pixels progressive scan at 50 frames per second), 1080i25 (1920x1080 pixels interlaced at 25 frames per second) and $1080 p 50(1920 \times 1080$ pixels progressive scan at 50 frames per second). While the 1080p50 standard offers the biggest difference in picture resolution (about five times as high) and smoothness in image flow (twice as fast) compared to interlaced PAL, its not yet been chosen as the common standard for HDTV in Europe. Instead, in 2004, 720p50 (preferred) and 1080i25 were advised by the European Broadcasting Union as the standards to be used for the near future, because $720 \mathrm{p}$ was in line with the standard that manufacturers used for TV sets but broadcasters still used interlaced techniques (EBU, 2004). These two standards have also been the basis for manufacturers, which, in 2006, made a European license agreement on selling HDTV compatible TV sets: A set that was sold with an "HD-ready" logo should be able to display 720p50 as well as 1080i25 images an have an aspect ratio of 16:9 (EICTA, 2006).

But having an EBU advice on standards and an industry agreement on display requirements does not mean that its 
introduction in society is simple and wanted by every party in the Dutch television chain. For the classical television form, where broadcasting still plays the central role, switching to HD requires technical investments in the whole television supply chain. Producers and broadcasters need to replace or upgrade their cameras, infrastructures, storage facilities, post-production and play-out equipment. Distributors need to switch from SD to HD transmissions, which will cost them more bandwidth, depending on the used compression technique. For the viewer, to view broadcast HDTV images, a HD-compatible television screen (following the 'HD-ready' requirements set by the industry) is necessary, but also a set top box that decodes HDTV content send by cable, satellite or terrestrial distribution channels. The realization of these technical changes depends on institutional choices and decisions. To understand why some of these decisions (like selling HD compatible TV screens) have been made while others (like broadcasting high definition content) have not, the next section will provide a theoretical framework on factors influencing innovation development and diffusion, as a basis for empirical research.

\section{Factors influencing diffusion}

On a macro level, the innovation development and diffusion process is often regarded as a result of technology push- and/or demand pull forces, where either the demand side is in need of a new technology or the supply side tries to create a market for it (Braun-Thürmann 2005). These theories, however, do not explain the factors behind these forces, nor why some technologies emerge but do not, or only partially, get diffused. Looking especially at the emergence of media technology, Hard (1993) and Winston (1998) state that the way a technology gets developed and diffused is a result of institutional conflicts rather than consensus, whereby stakeholders can regard the innovation either as an opportunity but also as a thread to their own business. In understanding the development and diffusion of HDTV, underlying factors influencing these different stakeholders must be addressed. Taking an economic perspective, strategies of stakeholders depend on the willingness to maintain existing positions among competitors, the strategies and power of suppliers and customers on which they depend, the threat of new competitors and the threat of substitute products or services (Porter, 1979). Next to these external forces, from a socialorganizational perspective, an institution itself can be regarded as an "arena" with different departments, visions and interests that, together or separately, shape different products and strategies (Braun-Thurmann 2005, 25). Also, from a historical point of view, there is the concept of 'path dependence', meaning that strategic decisions made by actors in the past have their impact on the choices there are for these actors in the present. (Arthur 1989, Liebowitz \&
Margolis 1995). Path dependence is not only a matter of money, where financial investments in one technology rule out later investments in another. It should also be seen as a matter of politics, where past experiences with innovation, either positive or negative, lead to a certain attitude towards new technologies and strategies. Also, taking a cultural perspective, it can be said that institutions, apart from actively promoting their own products in their own opportunistic ways, are themselves part of a collective belief system, or 'technological imaginary' (Lister et al. 2003, 60) of future uses a technology can bring about. Choices in investments of the television supply chain are partially shaped by these beliefs, since they can be seen as an organizations' basic set of expectancies regarding trends for future television. From within this system, depending on its own core business, an organization chooses its own position. Furthermore, serving as boundaries outside the television chain, government rules and regulations as well as scientific technical developments are worthy to mention, because these factors determine the realm of possibilities in which institutional choices are made.

\section{The Dutch (HD)TV chain}

Before looking at factors influencing the HDTV supply chain, the four major institutional groups in this chain are introduced. First, hardware manufacturers create and sell television screens, TV side equipment and set top boxes (that decode broadcasted digital signals to TV images). Secondly, content producers make programs and films and sell these to film distributors or television broadcasters. For the latter, producers can work in cooperation or independently from broadcasters. These broadcasters turn this content into channels and sell these to distributors. In the Netherlands, one public broadcasting company called 'Nederlandse Publieke Omroep' (NPO) and two commercial based broadcasting parties called 'RTL groep' and 'SBS broadcasting' are present, having each three main TV channels. The organizational structure of NPO is different from those of RTL and SBS in that it consists of 24 smaller broadcasting parties that represent different political and religious ideologies. Forth, cable distributors are the most important distribution party, since 90 percent of the Dutch public has a television subscription by cable (TNO, 2006). The three largest cable companies are UPC, @Home and Casema that together serve about 87 percent of the Dutch households in different regions (vecai.nl). Since the uptake of digital television in the Netherlands, competition, however, has started to come from two telecom operators that offer terrestrial TV (KPN) as well as IPTV (KPN and Tele2) and from the satellite operator CanalDigitaal. Following the roles and/or products of the stakeholders mentioned above, HDTV diffusion on the supply side depends on devices, content production, broadcasting and distribution. To understand this diffusion, current offers, strategies of stakeholders and underlying factors are 
analyzed. Information is derived from other research documents, interviews or conversations with CEO's and business managers of different stakeholders, newspapers and corporate websites.

Devices - When looking at the current development and diffusion of devices, a distinction should be made between TV sets, set top boxes and other peripheral devices. Starting with TV sets, almost all of the flat LCD- or plasma TV sets that are sold in the Netherlands have been labeled "HDReady' (van den Oever 2006) As described before, this label is the product of an international agreement between manufacturers to reduce the risk of making TV sets with a standard that might not survive. Also, the HD-Ready label can be seen as a way to stimulate consumers to buy new television screens, since it gives these TV's the promise of a high quality image. In 2006, the penetration of HD-Ready screens in households was about 12\% (Emerce 2006a). Since almost all TV sets that are available in shops are labeled HD-ready, this number will keep rising with every customer that buys a new TV, regardless of the reason why. But while HD-Ready screens have been dominating the TV market for the past two years, the new 1080p standard, referred to as 'Full HD', is now also being sold in electronics shops. The rise of this new standard does not have to affect current HDTV diffusion because, since it can also display 720p and 1080i signals and future 1080p signals can be down converted by set top boxes to be shown on HD-ready screens. However, the existence of both labels can be confusing for the public, causing them to wait until it becomes clear what standard will be the main one, especially since a 'Full HD' television set, with prices starting from around $€ 1200$,- or higher, still cost about 30 to 60 percent more than a 'HD-ready' set of the same brand with the same aspect ratio (Vergelijk.nl).

While TV sets have either HD- or Full HD compatibility, of the set top boxes for digital TV that are currently sold, only two models (Samsung and Philips) are HD-compatible and are by bought by Dutch cable companies that, in turn, sell them with their subscriptions. Reasons why manufacturers have not decided to make all set top boxes HD compatible (like they did with TV screens) can be found in technical/economical and strategic considerations: making set top boxes HD compatible is more costly than it is for TV sets, since set top boxes have to decode the signal which requires extensive processing power. The technique that is placed within the set top box depends highly on requests by (for the Netherlands) cable distributors that ask for cheap set top boxes with different functionalities. Making all of these set top boxes HD compatible would make them more expensive and less attractive to buy.

Apart from TV screens and set top boxes, devices that play a role in the HDTV diffusion are DVD players. While these devices are not part of the 'broadcasting' chain, viewers that have seen the HD image on their TV sets may actively start asking for broadcasted HD content. At this moment, both DVD players and game consoles have HD compatible variants which are for sale in the Netherlands. However, both devices come with different standards because in the United States, a battle is raging between the 'Blu Ray' (Sony / Philips) and the 'HD DVD' (Microsoft) standard (Laan 2007). This makes it harder for the public to buy a device, since there is a risk that it will become worthless.

Content productions - While manufacturers succeed in selling HDTV compatible TV sets, currently no Dutch HDTV channels or single HDTV programs have been broadcast. The main explanation that is given by public and commercial broadcasters is the small amount of available productions in HD-format. Investments in new equipment, software and facilities for production and postproduction haven't been done by most producers. According to the advisor of the Technology and Distribution Department (T\&D) of NPO, to produce in high definition still costs 15 to 20 percent more than producing in SD (Verhagen, 2007). For producers that work by request of broadcasters there is no hurry to replace their equipment, since those broadcasters - public and commercial alike - have not yet themselves made the step to show HDTV content on a regular basis. According to the CEO of the commercial TV producer ' $\mathrm{Xi}$ ', producing in HD standards will only take place when broadcasters decide to buy and broadcast HDTV instead of SDTV productions (van Dommelen, 2007). Furthermore, while Dutch program formats are sold to on a world wide scale, actual produced material from the Netherlands does not because of the Dutch language. Producers therefore depend mainly on Dutch broadcasters. There is, however, a small amount of Dutch high definition content available, coming from independent filmmakers and television producers (examples are 'Pipo en de p-p-Parelridder', '0605', 'Zwartboek' and 'Het Schaep met de Vijf Pooten') and also from under the analog 'HD-MAC project in the early 90's. For this HD-MAC project, about 74 programs have been made in high definition (NPO, 1996). This material can still be broadcast, although extra efforts have to be made in collecting this material now shattered within NPO and then converting the tapes to the new digital format (Noort, 2007).

Programs and films that are regularly broadcast in the Netherlands come, however, not only from the Netherlands but also mainly from the United States and countries within Europe. In the United States, many film productions as well as popular television series like 'Greys Anatomy' and 'Desperate Housewives', which are bought and broadcast by commercial Dutch broadcasters are produced in high definition,. In the United Kingdom, the BBC set up its own HD test channel with productions (BBC High Definition website) and has broadcast the Wimbledon tennis tournament in high definition (Oosten, 2006). More international sport events have also come from the Flemish audiovisual registration company 'Alfacam', which records the Olympic Games, several car tournaments and World Soccer Games in HD (Alfacam.com). Recently, French television has broadcast the international annual biking 
championship (Tour de France) in HD as well 2007 (Kriek, 2007). Except for the World Soccer Championship, none of this live and recorded content has been broadcast in HD in the Netherlands.

Content Broadcasting - Following the analysis above, it can be concluded that, although the amount of Dutch HD productions is limited, there are some national and international high definition productions that could, in theory, be broadcast in HD format by Dutch broadcasters. Why this still isn't done can be explained by factors that are different for public and commercial broadcasters. To start with the public broadcasters, according to Verharen, there is still work to be done before transmitting HDTV content to the public: "To be able to broadcast HDTV material on a somewhat regular basis, the internal infrastructure, which makes it possible to exchange and store productions, has to be completed first. Also, there is still some misunderstanding when in comes to standards. While the T\&D department wants use 720p as a standard, some producers still think the standard is 1080i." (Verharen 2007)

While the latter issue of standards could easily be solved by communicating with (internal) broadcasters and their producers, the first one is important to solve before broadcasting HDTV programs on a regular basis. Because of a physical fragmentation of NPO, a virtual infrastructure has been made in 2005, which is now used for play-out and archiving of productions. When this infrastructure is not HD compatible, changing to the $\mathrm{HD}$ format will result in practical internal transport problems and resistance to use this format. But this technical issue does not explain the fact that there haven't been any transmissions on an experimental basis. With the small amount of available HD productions and their experience with broadcasting the Soccer Games in 2006, NPO could, like the BBC, have made a separate 'carousel' channel. This would have been a motivation for internal producers to invest in HD equipment and a way to experiment outside of regular SD broadcasting. Also, it could have made the introduction of HDTV more visible to viewers, mainly because of the announcements of HD programs being broadcast. According to Verharen, there are two reasons why this hasn't been done. First, simultaneously transmitting the same program in SD and HD requires broadcasters to pay double for their broadcasting rights. The same goes for repeating programs on this carousel channel (Verharen 2007). This problem lies not in Dutch copyright law per se, since the Dutch copyright law states that the simultaneous broadcasting of the same content by the one institution is seen as only one 'publication' (Auteurswet, 1912). Instead, it has been made a problem by producers that mark their HD program as a new work of intellectual property next to the SD variant. More than law restrictions, making fair agreements are necessary to get this legal problem out of the way. The second, more profound, argument is a lack of belief in the positive effects of a carousel channel. According to Verharen, creating a separate HD channel is not helping producers nor viewers to switch to HDTV:
"With every new production, our broadcasters will then say 'oh just put it on the HDTV channel'. It will then take only longer before we can make the full switch to HDTV. Also, I don't believe that the public will watch this channel, considering the small amount of content it can provide. It is therefore better to wait until we have solved our technical, legal and content problems." (Verharen, 2007) This quote shows disbelief in the effect that the carousel channel has on motivations of broadcasters and the public to switch to HDTV. Reasons for this disbelief can be explained by the organizational structure and past experiences of NPO. First, the power of the T\&D department is limited because the execution of their plans depends on the will of a directory board on one hand as well as that of the different smaller broadcasters, which have separate strategies and are concerned with making regular programming for the coming season instead of long term investments (Baaren, 2006). Because of this organizational structure, beliefs the success of a carousel channel are low. Another factor that could influence reluctance to start such a channel can be found past experiences of NPO regarding HDTV and digital television. Within 15 years, there have been experiments and promotion projects regarding the HD-MAC standard, widescreen TV (Noort 2007) and digital interactive television, which have not lead to a short-term adoption of the technology by broadcasters and/or viewers. According to Kees Noort, senior director of the T\&D department, these events made the public broadcasters more careful: "The analog standard did not make it and the diffusion of the widescreen TV took about ten years longer then we expected. People involved in the old projects have been licking their wounds. So we rather do not attract too much attention in switching to HDTV, because then it will be worse when something goes wrong." (Noort, 2007) This citation shows that, apart from economical, technical and copyright arguments, beliefs in the positive results of a quick switch to HDTV are hardly there. With a budget that has shrunk due to cutting almost half of the funds by the ministry of OC\&W in 2006 (van der Laan, 2005), financial investments are carefully considered and will only be done when seen as absolutely necessary and worth the effort. This does not mean, however, that NPO does not come into action. While there is carefulness on one side, on the other side, there is the belief that switching to HDTV is, indeed, necessary. Since NPO has a task to keep serving its citizens, HDTV needs will be invested in "not so much because we want to generate more viewers, but because we certainly don't want to loose the ones we have." (Verharen, 2007). To realize this, in the spring of 2007, NPO has applied for financial support to the ministry of Economic Affairs in order to buy production equipment. If this support is given, the company plans to start broadcasting HD content on their regular channels in the beginning of 2008 (Verharen 2007).

Like public broadcasters, commercial broadcasters and producers have to invest in HD compatible equipment as well. But while the organizational power structure of the RTL group and SBS broadcasting is more centralized and 
there is no 'post-innovation trauma', no step has been taken to broadcast HDTV content so far. This is, as described before, not only due to lack of content. Especially with both companies regularly broadcasting American series and films, the switch to HD lies not in content but in economical motivations from broadcasters. The main argument for these broadcasters is that they simply see no extra profit to gain from the step to HDTV (De Jong, 2007) Since commercial broadcasters get their income from advertisers, especially the amount of viewers and viewing time is what leads decisions commercial broadcasters. These broadcasters will thus only switch to HDTV when old equipment has to be replaced anyway or when other broadcasters start transmissions in high definition, creating the idea that they can no longer stay behind.

Distribution - With broadcasters reluctant to switch to HDTV, there is hardly any Dutch HD content for distributors to offer to the public. Nevertheless, since June 2006, (at least) three major cable distributors, UPC, Casema and@Home, offer digital TV subscription packages with HDTV content as an extra (pay TV) option. This content consists of three of four channels that are - not surprisingly foreign owned: Discovery Channel (US) National Geographic Channel (UK), HD1 (Flanders) and in some cases Film1 (Chellomedia / Liberty Global, U.S.). Unlike cable companies, satellite provider CanalDigitaal, and telecom operators KPN and Tele2, do not offer HDTV subscriptions. However, viewers with a CanalDigitaal as well as non-subscribers with a satellite dish can receive freeto-air HDTV channels coming directly from the Astra satellite. These channels are HD1, pro7 and sat1 (German), BBC HD (British) and an Astra demo channel (CanalDigitaal.nl, 2007). This situation, in which cable distributors offer HDTV subscriptions whereas telecom and satellite (subscription) providers do not, is an effect of policy choices based on economical and technical grounds. First, since cable companies already possess $90 \%$ of the market and are geographically bound, creating conditions that 'enhance' existing subscriptions is to only way to make extra profit. However, the digitalization of television makes room for other ways to gain new income as well, like, for example, offering more channels, interactive applications, and Video On Demand (VOD) (van Vliet, 2001). The choice to exploit HDTV next to these other new channels and services, can be better explained by a second reason, which has to do with recent competition. Since the beginning of 2000, as a result of digitalization of TV, the monopoly position of cable companies have become less secure because telecom operators, in the expectancy of more fragmented media use by their customers (Mueller 2006), started to offer triple play services, which included digital television. Not bound to geographical areas for TV distribution, these operators posed a new thread to cable companies, especially since these telephone companies work with Internet protocols, making it easier for them to realize VOD or interactive applications by a return channel (van Vliet, 2001). HDTV is, however, a technology that is harder to use for these telephone lines, since it uses about three times as much bandwidth as SDTV (Miller, 2006). Having more bandwidth than telephone companies as well as satellite providers, HDTV can be used as a tool to keep cable customers from switching to other providers. This technical bandwidth issue does also explain why telecom operators choose to focus on 'on demand' and interactive services rather than HDTV.

The current visions and policies of distributors as described here do not mean that cable companies are fully HDTV oriented. This becomes clear when considering the recent rollout of set top boxes for digital television, of which none have HD-compatibility. Also, when looking at the offers from the websites of UPC and @Home, HDTV packages are offered next to Digital TV packages (@Home.nl, UPC.nl). The reason for distributors to keep focusing on DTV next to HD is because HD set top boxes are more expensive, but also because cable distributors are still occupied with the rollout of digital TV itself. This rollout had a slow start in the beginning of 2000 because of a relative good quality of analog TV and of a Dutch public that did not want not to pay much extra for digital TV subscription (Baaren 2006). With 35 percent of Dutch households watching digital TV in 2007 (Ernst \& Young, 2007), distributors are still occupied by this uptake. According to the CEO of Casema, for his company, getting the public to switch to DTV still has priority over HDTV, because cable bandwidth will become scarce as soon as more HDTV channels become available by broadcasters (Lieverse 2007). A quick full switch to HDTV can thus result in technical problems. An analog cable switch-off can solve this, but this requires a big majority of households to have switched to digital television. The result of this parallel DTV and HDTV rollout is that most of the households that have already changed from analog TV to DTV, have to order a new decoder if they want to watch programs and films in high definition. Efforts to change set top box as well as subscription within a short period of time can be perceived as 'too much to soon'. Moreover, cable distributors have switched strategy at beginning of 2006 and are now (except for UPC) selling these decoders through retail instead of giving them away. Households that indeed have paid for these decoders will be even less eager to buy a new one.

Apart from the late rollout of digital television, another factor is influencing distribution strategies of cable companies. Next to HDTV subscription packages, DTV subscriptions with VOD-like services are now offered and set top boxes with hard disc drives (to which content is sent and then locally stored) are now sold. Again, none of these set top boxes are HD compatible, making VOD and HDTV compete for customers rather than co-exist within a single subscription form. This two-path strategy by cable distributors can be seen as a result of uncertainty on future 
uses of digital TV. According to Lister et. al (2003), the imaginary of digital TV in the 90's consisted of high quality images as well as on demand applications, and with the expectancy of a fragmented market, both cable distributors and telecom operators, of which Tele2 now has plans to also offer HDTV movies on demand (Toekook, 2007), are betting on more than one horse in order to win, or at least stay in the race.

\section{Conclusion}

This article has shown that, when looking at the diffusion of an innovation, seeing this innovation as a product of a linear process of push- and pull factors is not enough, because even institutional decision making alone is based on many different factors. From an economical perspective, manufacturers have been the only ones 'pushing' in search for a new market, resulting in sales of HD-based TV sets, DVD players and game consoles. This search has, however, also resulted in the existence of different standards in TV sets (HD-ready vs. Full HD) and peripheral equipment (HDDVD vs. Blu Ray). Secondly, cable companies started offering HD subscriptions in order to compete with telecom distributors. Third, television producers that have not yet invested in new $\mathrm{HD}$ equipment because there is no channel to show their HD production (so there is no need), and broadcasters, in turn, also have to invest in equipment without expecting more viewers. Furthermore, behind these economical considerations lie cultural, organizational and above all, historical factors: Public broadcasters are hesitant because of their organizational decentralized structure and negative experiences from the past. In this past, political decisions (the dead end of analog HD) and cultural situations (slow adoption of widescreen and digital TV because of relative satisfaction with the analog 4:3 TV signal) have played an important role. For distributors, the late adoption of digital television as well as imaginaries of future digital TV uses cause them to follow more than one strategy in order to keep 'all options open'. So, when researching diffusion of innovation from an institutional perspective, whether this is HDTV or another innovation, contextual and historical factors must always be taken into account.

For the current practical diffusion of HDTV, it can be concluded that competing standards, competing TV uses and a shortage of Dutch content make HDTV still a niche for the supply chain to invest in. This has resulted in a stagnation of its diffusion and will have its effects on its adoption by the public as well. In the short term, while different standards and other TV-uses will keep competing with HDTV as long as set top boxes and side equipment do not combine these standards and services, a short term breakthrough in the lack of $\mathrm{HD}$ broadcasting might lie in the motivations of NPO to invest in production equipment and start showing in HD content at the beginning of 2008. But because of carefulness and a tight budget, the realization of these plans will depend on decisions for extra financial support from, for example the Dutch Government. The question remains, then, if this Dutch government sees a need to boost the diffusion of HDTV. Representing a country that bases its economy on selling knowledge by taking an international lead, or at least by not getting too far behind, one could say yes. Another consideration can also be made. Since television, from a government's perspective, can be seen a medium through which citizens get educated and informed about the world, the question should be asked if and how a sharper and a widescreen can contribute to this purpose.

\section{References}

- B. Agterberg, "Screening in High Standard. Innovating Film and Television in a digital Age through High Definition" in: Information Communication Technologies and Emerging Business Strategies, S. van der Graaf \& Y. Washida, Ed. Hershey \& London: Idea Group, 2007, pp. 191-207.

- Alfacam.com, http://www.alfacam.com, last visit September 7th 2007

- W.B..Arthur, "Competing Technologies, Increasing Returns, and Lock-In by Historical Events," The Economic Journal, vol..99, no. 394, March 1989, pp. 116-131

- E. Baaren, "Achter de Schermen van iTV. De institutionele ontwikkeling van interactieve digitale televisie in Nederland", Master thesis, Utrecht University, 2006.

- BBC High definition, http://www.bbc.co.uk/hd, last visit September 7, 2007

- W. Boddy, "Redefining the Home Screen: Technological Convergence as Trauma and Business Plan," in: Rethinking Media Change. The Aesthetics of Transition, D. Thornborn,. en H. Jenkins, Ed.,. Cambridge: MIT Press, 2003, pp. 191-200

- E. Boogert, "Nederlandse Verkoop HDTV verzesvoudigt in 2006," Emerce, June 14th 2006(a)

- E. Boogert, "Internetproviders niet klaar voor HDTV," Emerce, July 14th 2006(b)

- H. Braun-Thürmann, Innovation, Bielefeld : Transcript, 2005, ch. 2

- CanalDigitaal.nl, http://www.canaldigitaal.nl, last visit September 72007

- Casema.nl, http://www.casema.nl/pagina/thuis, last visit September 7, 2007

- “Nederlandse Auteurswet 1912", Ministry of Justice, 1912, art. 12

- R. van Dommelen, Xie Entertainment, CEO, Expertmeeting Digital Television, private communication, June 2007.

- EBU, "Technical recommendation R112-2004", October 2004

- EICTA, “"HD TV’ Logo Agreement”, March 2006

- Ernst \& Young, "Electronische Programmagids populair," June 19, 2007, http://www.ey.nl/?pag=788\&nieuws_id=3012

- M. Hard, "Beyond Harmony and Consensus: A Social Conflict Approach to Technology", Science, Technology and Human Values, vol. 18, no. 4, autumn 1993, pp. 408-432.

- M. Hijink, "HDTV wil maar niet doorbreken," NRC Handelsblad, September 2, 2006, pp.27 
- J. de Jong, RTL Broadcasting, Manager Distribution \& Business Development, Expertmeeting Digital Television, private communication, January 2007.

- J. Kriek, "Tour de France voor de eerste keer in HDTV te zien," Satellietnieuws.nl, May 9, 2007, online: http://www.satplaza.com/wordpres/?p=1675

- M. Laan, "Strijd om opvolging DVD nog niet beslecht", Het Parool, September 4, 207, p.29

- S. J. Liebowitz and S. E. Margolis,. "Path Dependence, Lock-In, and History," Journal of Law, Economics and Organization, vol 11, no. 1, 1995, pp. 205-226.

- G. Lieverse, Casema, CEO, private communication, March 2007

- J. Libbenga, "Wel het toestel, nog niet de programma's", NRC Next, July 24, 2007, pp. 25

- M.O. van der Laan, "Mediabegroting 2006", Ministry of Education, Culture \& Science, Novermber 11, 2005

- M. Lister, K. Kelly, J. Dovey, S. Giddings \& I. Grant, New Media: A Critical Introduction. London: Routledge, 2003, ch.1

- M. Miller, How Home Theater and HDTV Work, Indianapolis: Que Publishing, 2006.

- E. Müller, "Access to the Living Room: Triple Play and Interactive Television Reshaping the Producer/Consumer Relation," in Information Communication Technologies and Emerging Business strategies, S. van der Graaf \& Y. Washida, Ed. Hershey \& London: Idea Group, 2007, pp. 179-190.

- K. Noort, Nederlandse Publieke Omroep, Senior Advisor Technology \& New Media, private communication, February 2007.
- Nederlandse Publieke Omroep, "Geproduceerde HDTV programma's per omroep", May 6, 1996

- L. van den Oever, "HD-Ready to take of in NL?," GFK presentation presented at Cross Media Café Workshop, June 13, 2006,

- M. Oosten, "HDTV uitzendingen WK voetbal en Wimbledon," Satellietnieuws.nl, March 23, 2006, online: http:/www.satplaza.com/wordpres/?p=1080

- M.E. Porter, "How Competitive Forces Shape Strategy," Harvard Business Review, vol. 57, no. 2 , March-April 1979

- G. Sombroek, "Koopwijzer HD-lcd tv's," Personal Computer Magazine, June 2006

- R. Toekook, Tele2/Versatel, Manager Production \& Interactive Platforms, private communication, March 2003

- UPC.nl, http://www.upc.nl/, last visit September 7, 2007

- E. Verharen, Nederlandse Publieke Omroep, Advisor Technology \& New Media, private communication, February 2007.

- Vergelijk.nl, http://www.vergelijk.nl, last visit September 7 2007

- H. van Vliet, "Where Internet and Television Meet. New Experiences for rich media," E-view, vol. 2 (1), 2001.

- B. Winston, Media Technology and Society. A history: from the Telegraph to the Internet,. London \& New York: Routledge 1998, ch. 